\title{
Integrating risk and knowledge management in human spaceflight programs
}

David M. Lengyel, The George Washington University, USA, dmlengyel@icloud.com

John S. Newman, The George Washington University, USA, snewman3623@icloud.com

Thomas A. Mazzuchi, The George Washington University, USA, mazzu@gwu.edu

\begin{abstract}
The National Aeronautics and Space Administration (NASA) established the Exploration Systems Mission Directorate (ESMD) in the 2004 timeframe to manage a new portfolio of programs and projects aimed at lunar return. To ensure an effective transfer of knowledge from NASA legacy programs, such as Apollo, International Space Station, and Space Shuttle, ESMD took an integrated approach towards managing risk and knowledge. This case study examines the implementation of ESMD's integrated risk and knowledge management (IRKM) framework in the 2005-2012 timeframe. An important and novel aspect of this approach was using risk records to identify knowledge gaps and support the creation and transfer of both tacit and explicit knowledge. This explanatory case study describes how the integration of knowledge management and risk management, at both the enterprise and project-level, creates value to both processes and can assist any organization in more effectively pursuing its goals. The case also investigates how coupling these two business processes can garner broader-based organizational support for knowledge management activities. This paper is about enhancing risk management but at the same time it is a front-line investigation of what it takes to successfully implement and sustain a knowledge management enabled learning organization.
\end{abstract}

Keywords: Risk management, knowledge management, integrated, NASA, space flight.

\section{Introduction}

This case study provides an overview of the implementation of an integrated risk and knowledge management (IRKM) framework for the Exploration Systems Mission Directorate (ESMD) at the National Aeronautics and Space Administration (NASA) in the 2005-2012 timeframe. The goals of this framework were to facilitate risk-informed decision-making, to promote learning from past programs, as well as capturing and sharing knowledge of current risk issues across the directorate. This research is relevant to many, if not all, organizations that manage a portfolio of programs/projects and must manage hundreds, if not thousands, of risks on a daily basis. Both risk and knowledge management practitioners should also find this study of interest.

After the tragic space shuttle Columbia mishap in early 2003, the Bush administration decided to retire the Space Shuttle as soon as the International Space Station (ISS) could be safely assembled. In parallel with shuttle transition and retirement, the administration signed off on a new flagship program, known as Constellation, with the goal of establishing a human-tended lunar base as a stepping stone for crewed missions to Mars. Human space flight managers at NASA were also challenged with sustaining a balanced engineering and scientific workforce, 
developing advanced technologies for lunar and Mars missions, and stimulating the U.S. commercial space sector to develop cargo and then crew transportation to the ISS (The Vision for Space Exploration, 2004).

Preceding the Columbia mishap, NASA had been criticized by the General Accounting Office for less than adequate capture and transfer of lessons learned (U.S. General Accounting Office [U.S. GAO], 2002). In this context, ESMD management developed a plan to use risk management processes to inform and guide knowledge capture and transfer (KCT) as a means of responding to GAO concerns and resolve some of the inertia associated with establishing knowledge sharing behaviors across the newly-formed directorate.

The KCT challenge was particularly challenging given that the Constellation program was being implemented with support from seven different NASA Centers, each with unique aspects to their engineering and risk management culture. The research question to be addressed by this study is: How did the integration of risk management and knowledge management inform each other to strengthen each core business practice?

\section{Literature Review Within A NASA Context}

NASA has employed both risk and knowledge management principals since the Space Act of 1958, which formed the organization. Early human space flight programs such as Mercury and Gemini were precursors to Apollo missions and allowed the agency to mitigate the risks associated with successfully landing humans on the lunar surface and returning them safely to Earth. The knowledge gained from these early missions was conveyed in many forms, including the transfer of critical employees to the Apollo Program as well as the capture of lessons learned in the form of design standards and validated operational flight and ground processes and procedures. To anchor this in a research literature framework, three literature streams, risk and knowledge management, will be briefly examined individually and then in an integrated fashion within a NASA context.

\section{Risk Management}

NASA defines risk as "the potential for shortfalls with respect to achieving explicitly established and stated objectives. As applied to programs and projects, these objectives are translated into performance requirements, which may be related to mission execution domains (safety, mission success, cost, and schedule) or institutional support for mission execution" (NASA Procedural Requirements, 2017; NPR 8000.4). In layman's terms, risks are things that might happen that could prevent you from, or support you in, meeting your objectives. The general form of a risk statement is specified in two parts: a condition and a consequence. The condition should represent the root cause of the risk: there is no uncertainty in the condition, because it exists today. The consequence is the good thing or bad thing (opportunity or threat) that may occur as a result of the condition. Continuous Risk Management (CRM) is defined as a cyclical and continuous process of identifying, analyzing, mitigating (plan, track and control steps), documenting and communicating risks as shown in Figure 1 below. In 1996, Carnegie Mellon University, under contract to the U.S. Air Force, synthesized the expanding body of knowledge in continuous risk management (CRM) in their extensive guidebook (Dorofee et al., 1996). 


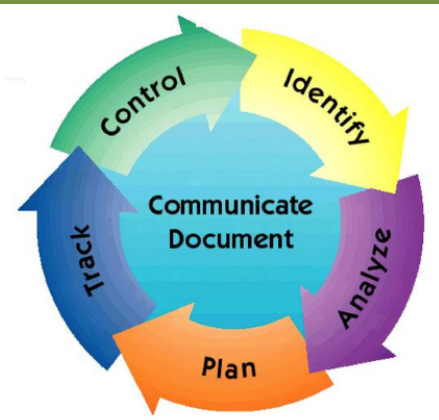

Figure 1. The Continuous Risk Management (CRM) Process (NPR 8000.4)

The discipline of Enterprise Risk Management (ERM) was inspired in part by the complexity of the global business and regulatory environment and also by the need for the internal controls function of large organizations to put in place a process to identify and manage risk. In 1992 the Committee of Sponsoring Organizations (COSO) of the Treadway Commission issued an integrated framework for ERM, which provided thought leadership for the ERM process for large organizations, COSO (2004).

ERM differs from program/project-oriented CRM in that it is applied in strategic settings, i.e. on the Chief Executive Officer (CEO) and board of director's level. It implies that the underlying risk process is executed and understood by senior management, that the portfolio of risks across business units is reviewed holistically in relation to the organization's risk appetite, that risks are managed comprehensively, and that it is integrated with other internal controls functions (e.g. audits) as well as strategic planning and execution (Gates, Nicolas, \& Walker, 2012).

\section{Knowledge Management}

Wiig (1997), an early KM thought leader, provided an assessment of the state of KM in 1997 noting that proactive organizations were systematically integrating $\mathrm{KM}$ as "part of their corporate practices" (p. 10). He observed that KM should be integrated with other processes rather than implementing KM as a standalone activity. Building on this approach, Dixon (2000) argued for an integrated framework for KM where "the way the target population benefits from participating needs to be direct and obvious to it" (p. 163). In concert with this, a nascent KM framework should be built upon existing systems, which may be enhanced to provide for the capture and transfer of knowledge.

ESMD looked to works such as "Working Knowledge," by KM pioneers Davenport and Prusak (2000), to guide their effort in knowledge capture and codification. Stewart (2001) suggested defining and locating an organization's knowledge assets and knowledge transactions. This includes the identification of knowledge gaps, which in many programs are also identified as risks. In this sense, "knowledge assets transform raw materials into something more valuable" (Stewart, 2001, p. 300). Prusak and Weiss (2007) noted that many early KM efforts relied too heavily on technology solutions and lacked a focus on what knowledge was most important in the organization. Risk management processes, by their very nature, are designed to identify critical knowledge gaps.

In addition to literature reviews, ESMD sought to leverage experiences, successes and challenges faced by NASA's pioneering KM initiative, the Process Based Mission Assurance Knowledge 
Management (PBMA) program, sponsored by the safety and mission assurance (SMA) organization. The PBMA merged KM with an existent, agency-wide core business process (i.e. SMA) operating with a distributed network of center-based organizations. The leveraging of a core business process was indeed a key success factor in the PBMA implementation.

\section{Integrated Risk and Knowledge Management}

If commonly used risk management and knowledge management process flow charts were to be compared, they would share many of the same functions: identification, analysis, communication, and so on. The end goals are also similar: supporting organizational action, sharing knowledge and enhancing risk-based decision-making. Some researchers argue that risk management strengthens knowledge management (Zyngier, 2008) while others argue that corporate risk is managed better through knowledge management principles (Currie, 2003; Massingham, 2010; Neef, 2005; Webb, 2007). Rodriguez and Edwards (2010) determined that risk knowledge sharing improved enterprise risk management implementation. Alhawari, Karadsheh, Talet, and Mansour (2012) proposed a knowledge-based risk management framework for information technology projects to enhance risk identification, analysis and mitigation planning. In a comparative case study, Zyngier (2008) showed that a KM governance approach facilitated managing the risks associated with enterprise-wide KM implementation in an organization.

\section{Research Gap}

The concept of integrating risk and knowledge management is not new and yet several opportunities exist to better define the interrelationships. Following ESMD's lead in this area, Sarah, Dow, Vena, and Pallschke (2017) at the European Space Agency (ESA), reviewed the extant literature as a pretext to implementing an integrated RM and KM system within their agency. Sarah et al. (2017) concluded that there is a substantial relationship between the two processes and that principals of each can be applied to the other. In their extensive review of the integrated risk and knowledge management literature, Haltiwanger, Landeata, Pinto, and Tolk (2010) find that there are "convincing arguments that there is a substantial relationship between RM and KM" but that "best practices and hard lessons learned" should be captured as part of future research (p. 297). If fusion of the two processes is useful, what is a practical implementation framework to improve this synthesis and what steps should be taken to add value to these critical processes? Also needed are exemplars in establishing and sustaining these integrated processes. This case study was designed to answer these questions.

\section{Research Design and Methodology}

The research design used was an explanatory case study of ESMD, which was selected for its unique blending of risk and knowledge management practices. Each practice is examined in detail below.

\section{Setting and Methodology}

The ESMD was used as the research setting. Similar organizations outside of NASA were also assessed, i.e. ESA, through extensive networking with industry partners and the Department of Defense, but again none fit the IRKM framework profile precisely. As a result, a single, explanatory case study design was selected as the methodological approach, using IRKM 
practices as the unit of analysis. A qualitative analysis of the risks and opportunities offered and lessons learned was accomplished primarily using interview data. An analysis of secondary data, as well as the extant literature, was deemed sufficient to address the research questions.

\section{Data Collection/Analysis and Validity}

Primary data for this research was captured through twenty semi-structured interviews of both NASA headquarters-level and program/project-level personnel in ESMD, all of whom were part of the organization during the 2005-2012 timeframe. Due to the extended time period studied a noted limitation of the research stems from one or more memory biases. Controlling for this were consistency checks of responses across the interviewee sample set. A purposive sampling approach was used to select interviewees. The telephonic interviews (conducted primarily by one interviewer) generally lasted 30-45 minutes, with detailed notes to document inputs. Interviewees were asked to comment on the risks and opportunities associated with ESMD's integrated risk and knowledge management practices. Coding of interview notes focused on synthesizing risk and/or opportunity statements. After twenty interviews, inputs became repetitive and consistent and this number was deemed sufficient for the purposes of this study. While interviewee selection bias is a noted threat to the validity of inputs, it was necessary to select personnel familiar with the IRKM processes to capture relevant lessons. Secondary data was collected from historical NASA and ESMD risk and knowledge management planning documents, training materials, online knowledge capture products, and refereed journal articles. Aware of the threats to the quality of a single case study design, care was taken to ensure that multiple sources of evidence were used; in addition several reviews of the paper were conducted with a small group of former ESMD personnel, and a structured protocol employed to synthesize interview inputs (Yin 2014).

\section{Research Results}

In ESMD, risks were communicated vertically through a well-defined escalation process, while horizontal integration occurred through multi-tiered risk management working groups (RMWGs) and a risk review board structure. The network of risk managers was used to communicate not only risks, but also to create lessons learned and validated practices. These were considered critical for knowledge sharing across the directorate. Establishing a robust integrated CRM and ERM process was a prerequisite to adding knowledge management practices and tools. This effort was not without challenges and, as one former NASA manager noted, "There is a huge cultural resistance at NASA to do lessons learning in general. Employees tend to have a headsdown, schedule- and product-driven mentality."

Integrated CRM and ERM became the foundation for establishing various KM modalities such as virtual collaboration, knowledge capture and transfer, reflective team process improvements, and decision analysis training. An important and novel aspect of the IRKM approach was its use of risk records to support the identification and transfer of knowledge to specific risk owners and other program personnel. Risk records document each risk and consist of a risk statement, contextual information, risk score (likelihood and consequence), summary mitigation and fallback plans, as well as discrete mitigation steps to reduce the risk level. ESMD adopted the slogan "Moon, Mars, and Beyond," which inferred a long-term horizon for the development and operation of their portfolio of programs and projects. With this in mind, ESMD management 
decided to establish a knowledge capture capability early on to ensure safe and reliable operations. Less than adequate sustaining engineering support beleaguered the space shuttle program late in its program life-cycle and as Goodman (2005), a former NASA flight controller, pointed out, "inadequate understanding of systems performance history was cited as a factor in the Challenger and Columbia accidents" (p. 6).

\section{IRKM Framework Lessons}

The ESMD IRKM framework, initiated in 2005, took almost two years to mature. The framework was first and foremost a risk management system. As one interviewee recalled, "It was a big "RM" and little "KM approach." The goal was to make the KM practices indistinguishable from the standard risk management process steps. Each of these practices are specified in Table 1 below. Each practice will be discussed in greater detail, to include lessons learned and impact on risk management. One former NASA risk manager noted that, "IRKM was a powerful validation of the need to couple KM with a critical core business process that spanned the entire organization. KM does not succeed on its own because it can be so broadly defined in an organization. Unfortunately, in many cases, KM typically gets assigned to the organization's Chief Information Officer."

Another manager remarked that, "return on investment for IRKM had to start on the desk of the individual user. It had to help people accomplish work and not be viewed as simply something that management tells them to do to ostensibly work more effectively."

Table 1. IRKM Practices

\begin{tabular}{|l|l|}
\hline IRKM Practice & Goal \\
\hline $\begin{array}{l}\text { Dual-Hatting Risk Managers as } \\
\text { Knowledge Managers }\end{array}$ & $\begin{array}{l}\text { Provide a network for risk and knowledge management } \\
\text { communications }\end{array}$ \\
\hline Knowledge-Based Risks & $\begin{array}{l}\text { Fill knowledge gaps, enhance risk identification and } \\
\text { mitigation planning }\end{array}$ \\
\hline Knowledge Cafes & Real-time knowledge transfer on risk-related topics \\
\hline Wiki-Enabled Teams & Cross-directorate risk communication \\
\hline Riskapedia & $\begin{array}{l}\text { Wiki-enabled, crowd-sourced knowledgebase for risk } \\
\text { identification, analysis, mitigation planning, and training } \\
\text { information }\end{array}$ \\
\hline Process 2.0 & $\begin{array}{l}\text { Real-time work process support, risk and opportunity } \\
\text { identification and mitigation planning }\end{array}$ \\
\hline Facilitated Problem Solving and & $\begin{array}{l}\text { Real-time team decision-making support, facilitator and } \\
\text { decision tool training in support of risk-informed } \\
\text { decisions }\end{array}$ \\
\hline
\end{tabular}

\section{Dual-Hatting Risk Managers}

Risk managers across the directorate were dual-hatted, meaning that they held both risk and knowledge management responsibilities. Using this network of risk managers to capture and/or distribute risk-based knowledge required targeted training in facilitation, interviewing techniques, lessons learned report writing/editing, and online tools such as wikis. One risk manager stated that, "Dual-hatting risk managers served as a central nervous system for riskbased information flow." In harmony with the KM literature such as Davenport and Prusak 
(1998), program risk review boards were de-facto knowledge markets.

A former NASA headquarters manager observed that, "NASA is a decentralized organization and there are distinct cultural aspects at each NASA center that have to be dealt with for any change management initiative." Recognizing this, there were several organizational challenges that had to be addressed during implementation of this framework. The first was opening up access to all program risk information across the directorate in one database, with a goal to make the risk database simultaneously a knowledge database. It also required an extensive risk breakdown structure and tagging of risk records such that users could easily locate risk records and owners who had similar challenges. This had never been done before in the agency.

Lessons: Dual-hatting Risk Management Officers (RMOs) required a slow process of cultural change to enable the sharing of detailed risk records across programs. Tasking RMOs with both risk and knowledge management functions was a powerful force multiplier in identifying, capturing and transferring knowledge across the directorate.

Implementation Challenges: RMOs required initial and sustaining knowledge management training, which included interview and facilitator techniques, wiki and decision tool familiarization, as well as budget support. Because their primary responsibility was the risk management function in their respective programs/projects, RMOs were initially reluctant to take on more responsibilities and were dependent on directorate resources (personnel and funds) to accomplish KM functions effectively. Opening access to all risk records across ESMD performing organizations (to ensure risk knowledge sharing) took almost a year and required building trust across the community that these records would not be used inappropriately.

\section{Knowledge-Based Risks (KBRs)}

ESMD risk records were used to provide the basic information for a product known as knowledge-based risks - web-based, multi-media knowledge bundles that provided users with expert advice on risk control and mitigation strategies for specific technical risks. ESMD defined a knowledge-based risk as a risk record, with associated knowledge artifacts, that provides a storytelling narrative of how the risk was identified and then mitigated, with details on what worked or did not work. A knowledge-based risk was therefore a means of transferring knowledge within the context of the CRM process. As key risks were mitigated, particularly risks that were deemed likely to recur across other programs in ESMD, that knowledge was captured and transferred. As a former ESMD manager put it, "instead of a collect, store, and ignore approach associated with lessons learned databases, knowledge-based risks formed an active collection system of lessons learned that were continually reused and updated." However, one interviewee lamented that, "knowledge-based risks should have been transferred within ESMD but also integrated with NASA's overarching program/project management training curriculum and made available to the public to obtain a broader audience." Another former manager admitted that, "For knowledge transfer to function in an organization, you need an 'expeditor,' who should be part of the system engineering and integration group, which will bring tailored knowledge artifacts to the organization."

Lessons: The concept of developing a compelling story around a risk that had been mitigated was both a unique aspect of the entire IRKM effort and a powerful means of learning from both successes and failures. 
Implementation Challenges: KBR development required a disciplined process to identify key risks, develop a lessons learned narrative report, conduct video interviews, capture related materials, encapsulate in a web-based environment, and perform a detailed quality assurance process before going live. It was a labor-intensive and complex product and had to be funded at the directorate-level.

\section{Knowledge Cafés}

Noted KM expert, Gurteen (1998) is credited with the concept of "Knowledge Cafes." They were adopted by ESMD early on and proved to be an effective technique to socialize ideas within a large group and create buy-in to move forward with those ideas. A key feature of the ESMD's café technique was the discussions that identified risk issues and meaningful mitigation approaches. Cafes had a number of key features important to enhanced dialog, developing teamwork, managing risk and making risk-informed decisions. Interviewee inputs were synthesized and are shown below:

- Engaged all participants in contributing ideas through discussion

- Accomplished social networking

- Developed teamwork

- Surfaced collective knowledge of a group

- Was a welcome departure from PowerPoint presentations

- Led to tangible outcomes in the form of better decisions

- Synthesized a list of ideas on each topic area

- Led to a deeper understanding of others' views on ideas / issues / problems

- Created a well-socialized and synthesized path forward for making decisions

Lessons: One key success factor for the conduct of knowledge cafes was the careful development of the agenda ("menu"), which generally included a top-level theme, six major topics, and associated topic question sets. Facilitators (sous chefs) were encouraged to use structured and unstructured brainstorming to capture participants' inputs. During the final session of the café, each facilitator provided a synthesized out-brief to the entire group. This out-brief provided a final opportunity to get to the "big brain" of the participants and captured additional inputs and "I forgots." Another key success factor was rigorous time management by each sous chef to address each question and to keep the conversation lively and fun.

Implementation Challenges: Despite initial skepticism of the utility of knowledge cafes, RMOs took to the technique rapidly and adapted the technique to meet their own programmatic and technical requirements. For example, cafes were used to identify risk issues and how to mitigate those risks. Sous chefs were selected based on their proven ability as group facilitators and were provided stenographer support to capture inputs from each conversation. Facilitation training was required for this role.

\section{Wiki-Enabled Teams Lessons}

In their research of failure, Newman and Wander (2018) found that a strikingly common denominator of many, if not most, program/project failures is less than adequate communication and a lack of defined roles and responsibilities. Wikis were instituted in part to resolve those risks and became the backbone and primary method of online communication and collaboration across the directorate. Implementation methods were informed by research literature and 
benchmarking of organizations using virtual teams. Not only did teams keep their work posted to their respective wikis, but a great deal of cross-directorate communication was facilitated through the rich linkages between spaces as well. As one risk manager noted, "wikis were particularly useful for managing our multi-discipline program design reviews." The selfauthoring capability of wikis was a natural attraction and driving force for the younger employees to drive their development and integration. To encourage use of the wikis, ESMD established a bi-annual awards program for the best wiki spaces.

Lessons: Wiki rollout was initially uneven across the directorate. To resolve that issue a twohour wiki-enabled teams course was developed and taught at the program/project team(s) level. The course leveraged knowledge from a benchmarking effort (see below) and recommended that teams take an approach that structured their knowledge by defining a team charter, roster, schedule, processes information, data, and links to teams requiring their products and vice-versa. Once this was accomplished the value proposition for wiki-enabled teams took flight and the risks associated with poor communication and knowledge sharing were mitigated to a large degree. The interconnections and communication paths created by team-based wikis tended to flatten the challenges associated with a very hierarchical organization structure and promoted collaboration.

Implementation Challenges: Wikis were not part of the tightly controlled and engineering oriented suite of tools forced on ESMD programs and projects by the directorate's chief information officer. A free version of Confluence, a recognized leader in wiki tools was "discovered" by a handful of users at the Johnson Space Center and later added to the ESMD intranet. They benchmarked Fidelity Investments in Boston, Massachusetts, who also used this tool to determine a path forward for implementation. When this knowledge was melded into a course that could be taught across the directorate, startup transients related to wiki rollout by and large disappeared. A remaining challenge however was a directorate dictate that programs and projects also use the intranet portal pages for posting critical team information, which tended to increase the intranet workload. In hindsight, wikis should have been used from the start versus clumsy portal IT solutions.

\section{Riskipedia}

An internal, crowd sourced wiki space was developed to provide tools, techniques, validated practices, and lessons learned addressing the fundamental discipline of risk management. The Riskipedia wiki space was sub-divided into four principal sections, which had to be "seeded" with information before going live. The Risk Identification section provided taxonomies and checklists from multiple authoritative sources for identifying typical system hardware/software, programmatic, and systems integration risks. The Risk Assessment section contained information on both qualitative and quantitative tools and techniques for analyzing risks. The Control and Mitigation section provided expert knowledge and guidance for the development of rigorous mitigation plans in multiple technical and programmatic domains. Finally, the Training section provided a synthesis of risk management validated training materials from across the directorate. Riskipedia content authoring was permitted from anyone in the directorate, but was checked for accuracy by a moderator. Unfortunately, as one manager pointed out, "Directorate information technology access rules combined with export control regulations that were in conflict with the need to share this knowledge across the agency and the public sphere where a greater value would have been obtained. You cannot bury a resource such as Riskipedia." 
Lessons: User acceptance and awareness was a key lesson for Riskapedia. Once the piloting effort for Riskapedia was completed and a healthy amount of content had been posted, ESMD received calls from RMOs as well as the cross-directorate engineering community about whether it was OK to modify or add to content on the site. Given that the tool was "open" for selfauthoring ESMD agreed to this concept to increase acceptance and use of the site. Inputs from field centers helped to close knowledge gaps in the content.

Implementation Challenges: Riskapedia content development was resource intensive. The piloting effort went through several iterations before settling on a framework that mirrored the risk management process itself. It then became a matter of soliciting support at the program/project level for sponsorship of and assistance with content, which was then posted in wiki format on the internal ESMD intranet. A Riskapedia training course was developed to increase awareness of the tool, as well as to solicit self-authored inputs from programs and projects.

\section{Work Process Support}

ESMD acknowledged that risks not only resided in the programmatic, technology and operations domains but also in the everyday business and engineering processes used by teams. However, NASA team leaders in many disciplines, for various reasons, appeared to be reluctant to conduct postmortem discussions with their teams after critical events. "Process 2.0" was instituted as a reflective learning technique utilized by ESMD, which was derived from U.S. Army's After Action Review concept. Process 2.0 events were facilitated, highly structured, time-managed, process reflection team events designed to expose threats and opportunities and develop plans to mitigate or capture those events after key program/project milestones. A key element in establishing Process 2.0 as a routine event for teams was ESMD development of an online as well as face-to-face training for both the Process 2.0 method and facilitation techniques (i.e. structured brainstorming) for the risk management community.

Lessons: Process 2.0 was perhaps ESMD's most powerful tool for identifying and mitigating risks associated with team processes. Many engineers and program planning and control personnel were already familiar with Six Sigma process improvement techniques but were turned off by the excruciating level of detail, long time period commitment and requirement for a trained ("black belt") facilitator. Process 2.0 offered a light touch approach to obtain an $80 \%$ solution to identifying breaks in processes and the fixes required to mitigate those issues. A training course for facilitators, generally RMOs at the program and project level, was developed for Process 2.0 preparation and facilitator techniques, such as the use of structured and unstructured brainstorming, rigorous time management, and the use of a fishbone diagram in real-time to structure the discussion around process success and failure modes.

Implementation Challenges: The key implementation challenge was training enough facilitators at the program and project level to ensure that Process 2.0 events could be carried out after key design and development milestones. This training included the use of ThinkTank (see below) a meeting support software tool that complemented the use of the process fishbone diagram.

\section{Facilitated Problem Solving and Decision Support}

A key goal of the IRKM framework was to ultimately support risk-informed decisions. Decisionsupport services provided by ESMD-level personnel included training and mentoring individuals 
and teams in implementing multi-attribute decision analysis techniques. In the course of this training, risk management and other personnel were provided facilitator training on how to use tools such as ThinkTank (brainstorming and nominal group technique) and DecisionPlus (the Simplified Multi-Attribute Rating Technique and Analytical Hierarchy Process techniques). The goal was to build a cadre of personnel capable of supporting team decisions, formal analysis of alternatives, and decision forums such as program or project requirements control boards and panels.

Lessons: Perhaps more than any other process within the IRKM framework, it was believed that adding more discipline to the risk acceptance process through decision tools would provide the highest payoff for ESMD. After all, less than adequate decision making had been a proximate cause of all three major NASA human space flight mishaps (Apollo 204 in 1967, STS-51L Challenger in 1986, \& STS-107 Columbia in 2003). Part of the problem may have been cultural resistance to the use of decision tools and part was the perceived difficulty of using these tools. Having said that, team brainstorming using ThinkTank over time became a well-accepted practice and was deemed a success.

Implementation Challenges: The RMO community adopted the use of ThinkTank quite willingly due to its ease of use and acceptance by most program and project personnel. However, the community was ill prepared and lacked the gravitas to insert higher-level and more decisiontheoretic tools into trade studies or decision forums such as the program requirements control board. Perhaps a better target audience for tools such as DecisionPlus would have been the systems engineering/technical trade study leads.

\section{Discussion}

Risk and knowledge management practices were assembled as an integrated framework over a period of five years. As one NASA manager commented, "IRKM leveraged the codification of risks; particularly the mitigation plans and associated lessons learned. You cannot underestimate the power of writing things down, which creates a knowledge base for persons suffering similar challenges, i.e. risks."

Based on the evidence in this case, RM and KM have been shown to exhibit a reciprocal relationship. RM identifies knowledge gaps and $\mathrm{KM}$ is a means of identifying resources to fill those gaps. These resources help practitioners utilize either existing codified or tacit knowledge to aid in identifying new risks as well as constructing validated risk mitigation plans. RM identifies critical knowledge that must either be created anew or located within the organization or externally. Within this rubric, integrated RM and KM aligns with the needs of the organization. In assessing how the relationship serves to improve both processes, we conclude the two disciplines already coexist regardless of whether an organization explicitly defines them as such. However, in codifying and formalizing an integrated approach, an organization is more likely to derive the benefits of process improvement in both RM and KM. Stated more succinctly; the symbiotic relationship between RM and KM acts to help an organization better achieve its goals.

Interviewee inputs were synthesized and offer the following functional improvements to RM and KM: 
- Developed a common language for integrated RM and KM

- Filled knowledge gaps in program/project/enterprise risks

- Developed a risk information sharing culture

- Improved individual and team communication methods

- Enhanced and sped up business and engineering process improvements

- Exposed and developed collaboration opportunities across the enterprise

- Enabled locating subject matter experts (through the risk database)

- Improved analytical problem solving and decision-making

- Captured and shared validated/best practices

- Ensured the capture and transfer of risk-based knowledge

Interviewees also offered thoughts on the challenges to implementation:

- Overcoming cultural resistance to sharing detailed risk data across a large portfolio of programs and projects within an enterprise

- Overcoming cultural resistance to practicing lessons learning in general

- Setting aside time for reflective lessons learning in all programs and projects to avoid a heads-down, schedule and product-driven mentality

- Information technology tools and architecture should support cross-organization access to risk-based knowledge in a secure fashion to ensure effective knowledge sharing

- Risk Management Officers must be adequately resourced and trained to perform risk and knowledge management duties

\section{Epilogue}

After the defunding of the Constellation Program in early 2010, ESMD eventually was merged with the Space Operations Mission Directorate to become the Human Exploration and Operations Mission Directorate. The resulting change in directorate management, along with different funding priorities, eliminated enterprise risk management altogether and redirected monies for RM and KM products in an effort to reduce the NASA headquarters budget. This is not an indictment of senior NASA management, just recognition that management changes often result in these organizational shifts. Haltiwanger et al, (2010) created a conceptual model of RM and KM, which expose several integration "scenarios" useful for exposing the benefits of integration. They note that, "entities switch from scenario to scenario depending on their needs, capabilities, past experiences and personalities of the decision-makers," (Haltiwanger et al., 2010, p. 296). In 2012 ESMD slipped into the category of manage knowledge but not in support of risk management.

While there was insufficient run-time in exercising the ESMD IRKM framework to determine the efficacy of this specific implementation approach from a cost, schedule, technical, or safety metrics perspective, anecdotal evidence points to many success factors, as noted above. Elements of the framework exist today - continuous risk management at the program level, crossdirectorate wiki-enabled teams, and reflective learning and knowledge capture and transfer but they are no longer used in an integrated fashion as envisioned during implementation. Eventually, the Chief Engineer's office established a Chief Knowledge Officer who continues to develop and evolve knowledge capture and transfer products based on IRKM innovations. Given the IRKM initial success with strong sponsorship then diminished success with lost sponsorship 
it is clear that senior management support is the lynch pin to successful implementation.

\section{References}

Alhawari, S., Karadsheh, L., Talet, A., \& Mansour, E. (2012). Knowledge-based risk management framework for information technology project. International Journal of Information Management, 32(1) 50-65. http://doi.org/10.1016/j.ijinfomgt.2011.07.002

Committee of Sponsoring Organizations of the Treadway Commission [COSO] (2004). Enterprise risk management - integrated framework, executive summary, Committee of Sponsoring Organizations of the Treadway Commission, New York.

Currie, W. (2003). A knowledge-based risk assessment framework for evaluating web-enabled application outsourcing projects. International Journal of Project Management, 21(3), 207-217. http://doi.org/10.1016/S0263-7863(02)00095-9

Davenport, T., \& Prusak, L. (2000). Working knowledge: How organizations manage what they know. Boston, MA: Harvard Business School Press.

Dixon, N. (2000). Common knowledge: How companies thrive by sharing what they know. Boston, MA: Harvard Business School Press.

Dorofee, A., Alberts, C., Higuera, R., Murphy, R., Walker, J., \& Williams, R. (1996). Continuous risk management guidebook. Software Engineering Institute, Carnegie-Melon University. Retrieved from: https://www.gao.gov/new.items/d02195.pdf

Gates, S., Nicolas, J., \& Walker, P. (2012). Enterprise risk management: A process for enhanced management and improved performance. Management Accounting Quarterly, 13(3), 2838 .

Goodman, J. (2005). Knowledge capture and management for flight systems. NASA/CR-2005213692. Retrieved from: https://ntrs.nasa.gov/archive/nasa/casi.ntrs.nasa.gov/200502420 39.pdf

Gurteen, D. (1998). Definition of a knowledge café. Retrieved from: http://www.gurteen.com/gurteen/gurteen.nsf/id/kcafe

Haltiwanger, G., Landeata, R., Pinto, C., \& Tolk, A. (2010). Understanding the relationship between risk management and knowledge management: A literature review and extension. International Journal Knowledge Management Studies, 4(3), 281-300.

Massingham, P. (2010). Knowledge risk management: A framework. Journal of Knowledge Management, 14(3), 464-485. http://doi.org/10.1108/13673271011050166

NASA Procedural Requirements (2017). NPR 8000.4B Agency risk management procedural requirements. Retrieved from: https://nodis3.gsfc.nasa.gov/npg_img/N_PR_8000_004B N_PR 8000_004B_.pdf

Neef, D. (2005). Managing corporate risk through better knowledge management. The Learning Organization, 12(2), 112-124. http://doi.org/10.1108/09696470510583502 
Newman, S., \& Wander, S. (2018). Harnessing the power of failure: Using storytelling and systems engineering to enhance organizational learning. Bingley, UK: Emerald.

Prusak, L., \& Weiss, L. (2007). Knowledge in organizational settings. In Ichijo, K. and Nonaka, I. (Ed.), Knowledge Creation and Management, (pp. 32-43). New York, NY: Oxford University Press.

Rodriguez, E., \& Edwards, J. (2010). People, technology, processes and risk knowledge sharing. Electronic Journal of Knowledge Management, 8(1), 139-150.

Sarah, M-G, Dow, R., Andrea Vena, A., \& Pallaschke, S. (2017). Risk and knowledge management relationships at the European Space Agency. Proceedings of the International Aeronautical Congress (IAC-17), Adelaide, Australia, American Institute Federation of Aeronautics and Astronautics, Inc.

Stewart, T. (2001). The wealth of knowledge: Intellectual capital and the twenty-first century organization. New York, NY: Currency.

The Vision for Space Exploration (2004). A renewed spirit of discovery: The President's vision for U.S. space exploration. National Aeronautics and Space Administration (NASA) Headquarters, Washington, DC 20546, NP-2004-01-334-HQ. Retrieved from: https://www.nasa.gov/pdf/55583main_vision_space_exploration2.pdf

Webb, J. (2007), Risk management report: An essential tool kit for business. FreePint, 222, 2024. Retrieved from: http://www.freepint.com/issues/180107.pdf

U.S. General Accounting Office (2002). NASA: Better mechanisms needed for sharing lessons learned (GAO-02-195). Report to the Subcommittee on Space and Aeronautics, Committee on Science, House of Representatives. Retrieved from: https://www.gao.gov/new.items/d02195.pdf

Wiig, K. (1997). Knowledge management: Where did it come from and where will it go? Journal of Expert Systems With Applications, 13(1), 1-14. http://doi.org/10.1016/S09574174(97)00018-3

Yin, R. (2014). Case study research: Design and methods ( $5^{\text {th }}$ Ed.). Thousand Oaks, CA: Sage Publications.

Zyngier, S. (2008). Risk management: Strengthening knowledge management. International Journal of Knowledge Management, 4(3), 19-32. http://doi.org/10.4018/jkm.2008070102

\section{Authors' Biographies}

David M. Lengyel, Ph.D. Retired from NASA in 2014 after 21 years at the agency in human spaceflight serving in the Shuttle/Mir Program, International Space Station Program and Exploration Systems Mission Directorate. Previously he was an F-15 and FA-18 Aircrew Training Instructor for the McDonnell Aircraft Company. He accumulated over 2200 flight hours in the U.S. Marine Corps as a Naval Flight Officer in the F-4S Phantom II. Dr. Lengyel holds a B.S. from the U.S. Naval Academy, an MBA from the University of Missouri, an M.A. in International Affairs from Washington

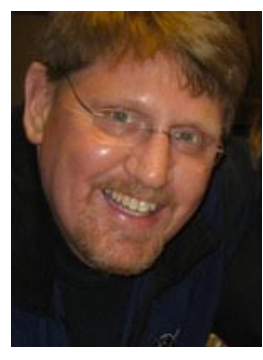


University--St. Louis, and an M.S. and Ph.D. in Systems Engineering from The George Washington University.

John Steven Newman, Ph.D. Had a distinguished 42-year career with NASA, the FAA, and as an aerospace consultant. His experience base spans the Concorde SST, the Titan IV launch vehicle, the Space Shuttle, and the International Space Station. Dr. Newman served in diverse leadership roles spanning project management, flight test, safety, quality, risk management, environmental management, and accident and failure analysis. Dr. Newman holds a B.S. in Electrical Engineering, and an M.S. Science in Environmental

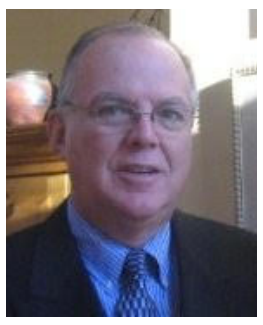
Engineering from Northwestern University, as well as a D.Sc. in Systems Engineering from The George Washington University.

Thomas A. Mazzuchi, Ph.D. Currently, he is a Professor and Chair of Engineering Management and Systems Engineering in the School of Engineering and Applied Science at The George Washington University, Washington, D.C. where he has also served as the Chair of the Operations Research Department and as Interim Dean of the School of Engineering and Applied Science. Dr. Mazzuchi holds a B.A. (1978) in Mathematics from Gettysburg College, Gettysburg, PA, an M.S. (1979) and D.Sc. (1982), both in Operations Research from The George Washington University.

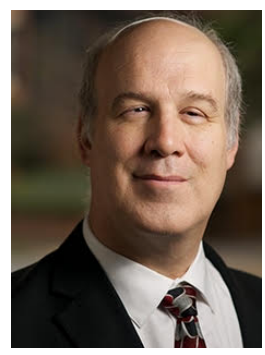

